\title{
A FOTOGRAFIA COMO ELEMENTO PEDAGÓGICO DE CONSTRUÇÃO E EXPRESSÃO DE CONHECIMENTOS NA TERCEIRA IDADE
}

\author{
PHOTOGRAPHY AS A PEDAGOGICAL ELEMENT OF CONSTRUCTION AND \\ EXPRESSION OF KNOWLEDGE IN THE OLD AGE
}

\section{LA FOTOGRAFÍA COMO ELEMENTO PEDAGÓGICO DE CONSTRUCCIÓN Y EXPRESIÓN DE LOS CONOCIMIENTOS EN LA TERCERA EDAD}

Rosângela Silva Oliveira*

\begin{abstract}
Resumo: Este artigo apresenta o valor de experiências pedagógicas com pessoas da terceira idade que utilizam a fotografia para a construção e expressão de conhecimentos das/nas práticas sociais. São ações educativas que exploram a fotografia como recurso pedagógico e objetivam provocar o olhar reflexivo do idoso sobre o ambiente físico e social em que está inserido; fortalecer habilidades de observação do entorno em suas múltiplas dimensões, permitindo a construção e expressão de ponto de vista pessoal; estimular sínteses pessoais comunicadas visualmente em diferentes ângulos; superar diferenças cognitivas individuais trocando as letras pela imagem, sem prejuízos de comunicação de opiniões, conviç̧ões e sentimentos; e estimular a autoconfiança do idoso baseado em seu potencial de comunicar sua visão holística pela fotografia. Partindo do questionamento “Onde estou?” os idosos foram orientados a retratar suas práticas sociais em diferentes ângulos através da fotografia e depois socializá-las em grupo comunicando suas percepções e aprendizagens. O método de abordagem foi o Dialético porque este atende práticas investigativas que analisam ambientes sociais em seus distintos aspectos e inter-relações. Os resultados apontam a ampliação da percepção dos idosos sobre o real, registrada em fotografias que comunicam o singular olhar reflexivo do idoso e seu potencial cognitivo, ativo para avaliar e comunicar situações includentes ou excludentes de espaços e sujeitos sociais.
\end{abstract}

Palavras-chave: Fotografia. Ação reflexiva. Envelhecimento ativo.

Abstract: This paper presents the value of pedagogical experiences with elderly people who use photography for the construction and expression of knowledge on social practices. These are educational actions that explores photography as a pedagogical resource and aim to provoke the reflexive thinking of the elderly on the physical and social environment in which they are inserted; strengthen observation skills of the environment in its multiple dimensions, allowing the construction and expression of personal point of view; stimulate personal synthesis communicated visually from different angles; overcome individual cognitive differences by exchanging letters for the image, without prejudicing the communication of opinions, convictions and feelings; and to stimulate the self-confidence of the elderly based on their potential to communicate their holistic view through photography. Starting from the question "Where am I?", the elderly were instructed to portray their social practices at different angles through photography and then share them in groups communicating their perceptions and learning. The method of approach was the Dialectic because it deals with investigative practices that analyze social environments in their different aspects and interrelationships. The results point to an increase in

\footnotetext{
* Doutora em Educação pela UFRN; Professora Adjunto do Departamento de Educação da Universidade Estadual do Maranhão - Campus Bacabal; e-mail: raltamira@ig.com.br
} 
the perception of the elderly on the real, recorded in photographs that communicate the individual 's unique reflexive view and their cognitive potential to evaluate and communicate including or excluding situations of spaces and social subjects.

Keywords: Photography. Reflective action. Active aging.

Resumen: En este artículo se presenta el valor de la experiencia de enseñanza con los adultos mayores que utiliza la fotografía para la construcción y expresión del conocimiento de(en) las prácticas sociales. Son actividades educativas que explotan a la fotografía como recurso pedagógico que busca provocar la mirada reflexiva de la persona mayor sobre el entorno físico y social en el que se inserta; fortalecer la capacidad de observación que lo que lo rodea en sus múltiples dimensiones, permitiendo la construcción y expresión de un punto de vista personal; estimular las síntesis personales comunicadas visualmente en diferentes ángulos; superar las diferencias cognitivas individuales cambiando letras por imágenes, sin perjuicio en la comunicación de opiniones, creencias y sentimientos; y estimular la autoconfianza de las personas mayores en función de su capacidad para comunicar su visión holística de la fotografía. A partir de la pregunta “¿dónde estoy?” se les pidió que retrataran sus prácticas sociales en diferentes ángulos a través de la fotografía y que luego las socializaran en grupos comunicando sus percepciones y aprendizajes. El método de abordaje fue dialéctico porque atendiende las prácticas de investigación que analizan los ambientes sociales en sus diferentes aspectos e interrelaciones. Los resultados muestran una alta percepción de las personas mayores sobre lo real, registrado en las fotografías que comunican la mirada reflexiva singular de las personas mayores y su potencial cognitivo, un activo para evaluar y comunicar situacionesincluyentes o excluyentes de espacios y sujetos sociales.

Palabras clave: Fotografía. Acción reflexiva. Envejecimiento activo

\section{Introdução}

A ampliação de ações educativas na terceira idade, proposto por projetos de extensão universitária, vem provocando diálogos investigativos sobre o lugar social do idoso, seu potencial cognitivo e potencialidades de envelhecimento saudável e ativo. Conforme estudos divulgados pela Secretaria Nacional de Promoção Defesa dos Direitos Humanos (BRASIL, 2016) este segmento populacional, predominantemente feminino no Brasil, tem alcançado um vertiginoso crescimento e as instituições públicas precisam se organizar em ações includentes para assegurar-lhes uma velhice humanizada.

A Lei Federal 10.741/2003 estabelece que é obrigação da família, da comunidade, da sociedade e do Poder Público garantir ao idoso a preservação de sua saúde física e mental em condições dignas, com liberdade e dignidade (ibid). Mas estes direitos fundamentais são preteridos no dia-a-dia da sociedade civil e política brasileira. Muitos idosos desistem de lutar por seu lugar social e isso é altamente prejudicial, pois o espaço de poder não fica vago. Se o idoso não ocupar seu espaço político, certamente outros o ocuparão, com graves repercussões para os direitos tão duramente conquistados em políticas públicas.

Como sujeitos históricos que são, precisam ser respeitados, valorizados e incluídos em todos os setores da sociedade. Num país como o Brasil, com um vasto contingente de pobres em todas as idades, com uma política de educação e saúde caótica, com benefícios previdenciários ínfimos, com a assistência social praticamente inerte e com um forte preconceito contra os idosos, não é difícil presumir porque muitos desistem de lutar pelo seu lugar social (ALVES, 2001; LIMA, 2000; MONTEIRO, 2001; VERAS, 1997). Entre os males sociais que enfrentam, os mais expressivos são de caráter relacional - são 
excluídos da vida cultural e da vida familiar ativa, destinados à penumbra da existência humana, silenciados como seres humanos (NERI, 1995).

A Universidade pode se constituir em locus privilegiado, porém não exclusivo, de reflexão e ação para provocar uma consciência comunitária da necessidade do exercício da cidadania na terceira idade. Foi neste propósito que a Universidade Estadual do Maranhão (UEMA) ofereceu como ação extensionista, a Universidade Aberta Intergeracional (UNABI) em seus Centros de Estudos Superiores para atender este segmento populacional desconfiado de políticas públicas que não se cumprem, mas curioso em conhecer a atividade intelectual do ambiente universitário.

No momento inicial de aproximação intergeracional as ações educativas propostas pela UNABI/UEMA - Campus Bacabal, foram desafiadoras em sua transposição didática. Seus resultados poderiam resultar na permanência ou evasão dos idosos. E aqui entra o valor didático do uso da fotografia em sala de aula como recurso pedagógico de construção e expressão de conhecimentos na terceira idade.

A fotografia foi especialmente explorada dentro e fora da sala de aula para socializar experiências de vidas, resgatar memórias, comunicar direitos sociais e provocar reflexões que não coadunam com qualquer tipo de violência ou preconceito contra o idoso. Esta experiência educativa será apresentada a seguir como um percurso metodológico possível de ser aplicado para construir e expressar conhecimentos simples e/ou complexos, mas apreendidos nas percepções e cognições deste segmento populacional.

\section{A educação para pessoas da terceira idade: fundamentos teórico- metodológicos do ato educativo na UEMA/UNABI - Campus Bacabal}

Pensar em educação para pessoas que já viveram mais de seis décadas exige responsabilidade social e comprometimento com práticas sociais que, em si, provocam o homem para o diálogo consciente e corajoso com o real. Consciente disso, a Universidade Estadual do Maranhão através da Universidade Aberta Intergeracional (UNABI) - Campus Bacabal, entende que somente em liberdade pode-se educar o homem como sujeito social que ele é ou que deveria ser.

Nesta perspectiva os fundamentos teórico-metodológicos deste ato educativo coadunam com o pensamento do educador brasileiro Paulo Freire (1999, p. 53) "A educação como prática da liberdade, ao contrário daquela que é a prática da dominação, implica a negação do homem abstrato, isolado, solto, desligado do mundo, assim também a negação do mundo como uma realidade ausente dos homens”. O ato educativo proposto na UEMA/UNABI Campus Bacabal fundamenta-se em uma pedagogia contrária ao alheamento de si e do mundo, permanentemente provocativa, investigativa e alfabetizadora porque o homem idoso vive em uma sociedade que privilegia a linguagem escrita. Entende-se que mesmo na terceira idade o homem precisa estar aberto para construir novas histórias e não apenas reproduzi-las.

A educação para idosos, oferecida de forma sistemática ou não, tinha como eixos basilares a cultura da ação dialética com respeito mútuo e responsabilidade social. Neste aspecto saber comunicar-se e comunicar o conhecimento tornou-se uma arte porque urgia ao idoso a aquisição de um feixe de habilidades cognitivas para interagir com conteúdos 
sócio-culturais contextualizados e resultarem em competência comunicativa. A singularidade da comunicação em suas distintas formas de expressão horizontalizadas foram marcos educacionais perseguidos cotidianamente em todas situações pedagógicas.

O letramento na terceira idade se constitui um direito humano absoluto, independentemente da escolaridade e condições econômicas (SOARES, 1999, p.80). O saber do idoso, em suas distintas formas de manifestação, não pode ser negado.

Aprender na UNABI/UEMA foi e é compreendido como uma (re)descoberta criativa, significativa e útil. Entende-se que uma pessoa é funcionalmente letrada quando pode participar das atividades sociais de seu contexto, utilizando-se de variadas formas de comunicação e conforme suas possibilidades potenciais. Aprender é captar o movimento do real e seus determinantes (VASCONCELOS, 1999, p. 39), construindo significados capazes de serem comunicados em distintas linguagens e representações mentais.

As práticas educativas com idosos precisam ser humanizantes no sentido de desafiá-los a refletirem sobre si mesmo, antes de pensarem no ambiente em que vivem (BOTH, 2000). Os idosos precisam de auxilio pedagógico correto para libertarem suas emoções contidas, medos, traumas e passivos silenciamentos que sofreram ao longo de sua vida.

E no cerne deste trabalho pedagógico deve conter a ideologia de que ao contrário dos animais que são 'seres em si mesmo', os seres humanos são 'seres para si' e sofrem alta ação desumanizante quando são submetidos a práticas sociais que os tornam 'seres para o outro'. A pessoa idosa que se enxerga como uma pessoa que somente sobreviveu ou sobrevive as intempéries da vida não tem consciência de si, é ingênua e frágil como ser humano. (FREIRE, 1980; 1999; 2005).
Saber-se ser humano, capaz de expressar-se e expressar a realidade em multiformes linguagens são os fundamentos basilares de ações pedagógicas comprometidas com o cidadão brasileiro, mesmo na terceira idade. A desumanização social projetada para o idoso, mesmo sendo uma realidade vivida, não é, porém, um destino cristalizado.

Postula-se ações educativas que possibilitem o enfrentamento de seus medos e silenciamentos como força propulsora inicial para potencializar e valorizar sua história de vida - e a exploração da fotografia como recurso didático para identificar marcas de isolamentos e/ou mutilamentos culturais em diferentes épocas e/ou contextos, possui alto valor pedagógico.

Para o educador Paulo Freire os desumanizantes consideram apenas a si mesmo como ser humano - os outros, numa atitude possesiva do mundo e dos homens, são percebidos como coisas. Ficaram cegos em sua cobiça e não enxergam que já estão oprimidos em sua própria ação:

A violência dos opressores, que os faz também desumanizados, não instaura uma outra vocação - a do ser menos. Como distorção do ser mais, o ser menos leva os oprimidos, cedo ou tarde, a lutar contra quem os fez menos. E esta luta somente tem sentido quando os oprimidos, ao buscarem recuperar sua humanidade, que é uma forma de cria-la, não se sentem idealistamente opressores, nem se tornam, de fato, opressores dos opressores, mas restauradores da humanidade em ambos. E aí está a grande tarefa humanista e histórica dos oprimidos - libertar-se a si e aos opressores. Estes, que oprimem, exploram e violentam, em razão de seu poder, não podem ter, neste poder, a força da libertação dos oprimidos nem de si mesmos (FREIRE, 2005, p. 31). 
Reconhecer a existência da desumanização e seu caráter egoísta, possessivo, capaz de roubar a essência humana do outro, constituiu-se saber inicial necessário para a assunção de uma identidade cultural que não coaduna com praticas sociais imobilizadoras para o idoso.

Neste propósito considerou-se que a relação educativa do sujeito idoso x objeto de conhecimento não podia ser manipuladora, simplista, mecânica, antidialógica ou distanciada de reflexões sobre o ‘eu’ pessoal e social, pois tudo isso são táticas invasivas de dominação Ao contrário, a prática educativa proposta foi investigativa, interativa, significativa e consciente e possuía como essência da transposição didática a reflexão-ação-reflexão.

Os eixos metodológicos do cerne deste processo ensino-aprendizagem foram:

- a ação educativa não resulta de imitações, condicionamentos ou reflexos, mas da interação dialética do homem e seu ambiente sócio-cultural;

- o desenvolvimento mental humano se aperfeiçoa nas práticas sociais, nas relações interativas do sujeito idoso e na ampliação do autoconhecimento com autonomia e responsabilidade social;

- o conhecimento é construído dialeticamente pelo sujeito idoso na sua ação sobre um objeto de estudo, considerando a existência de distintos níveis e ritmos de aprendizagens.

Este paradigma educacional dialético, eleito para as práticas pedagógicas com idosos da UEMA/UNABI - Campus Bacabal permitiu que os sujeitos do processo ensino-aprendizagem, em relação de interdependência, se identificassem como sujeitos concretos, numa realidade concreta passível de ser revelada/ explicada em suas múltiplas dimensões.

\section{A fotografia em ações educativas para pessoas da terceira idade}

Entre distintos recursos de ensino os registros fotográficos revelaram-se de pertinaz importância pedagógica na terceira idade por permitir, em si mesmo e em seu potencial de comunicação intergeracional, distintas leituras, lembranças e reflexões interdisciplinares. “O papel da fotografia é conservar o traço do passado ou auxiliar as ciências em seu esforço para uma melhor apresentação da realidade do mundo” (DUBOIS.1994, p.30).

A fotografia agrega um alto potencial de comunicação social que provoca as pessoas para o diálogo espontâneo sem as amarras da normal culta padrão (KOSSOY, 2003). Como registro visual e material a fotografia apresenta-se com uma linguagem popular privilegiada que permite registros de momentos difíceis de serem resgatados com precisão quer seja pela língua falada ou escrita. Para a pesquisadora Maria Inês Sucupira Stamatto a fotografia é rica em informações culturais e não pode ser explorada didaticamente apenas como mera ilustração de um texto.

Devemos, contudo, ter o cuidado de não pensarmos a fotografia apenas como um complemento da informação oral ou escrita. Uma imagem fotografada possui informação da realidade registrada e, igualmente, historicidade. Por isso, uma fotografia é diferente de outros tipos de iconografia como pinturas, desenhos, gravuras e ilustrações, já que comporta dados de fatos objetivos da realidade apreendida, de lugares que existem ou existiram e de pessoas e sociedades que viveram em um momento determinado (STAMATTO, 2009, p.135).

A fotografia possui um caráter educativo porque captura um momento objetivo que aponta sinais de comportamentos subjetivos e costumes individuais e coletivos do sujeito 
pessoal e social em seu ambiente privado ou público. Em sua função didática aguça e amplia o olhar investigativo para o fato e seu contexto, exercita a capacidade de observação sistemática e provoca aproximações e avaliações distintas e sucessivas do real. Além disso ajuda compreender as sociedades e suas formas culturais de organização, portanto se constitui um documento sócio-educativo, uma memória visual construída sob diferentes ângulos e fins.

O idoso aprende mais com imagens visuais, sua linguagem é exercitada com mais fluidez porque a fotografia traz informações de situações que ele já viveu ou ouviu falar. Ele sente mais segurança ao emitir sua opinião olhando uma imagem do que lendo um texto escrito. Muitas vezes despreza as palavras para observá-la. Entretanto o educador social deve lembrar sempre ao idoso que a fotografia comunica intencionalmente apenas informações que o fotógrafo quer mostrar e a forma que ele escolheu para denunciar, sensibilizar, desnudar sentimentos, distorcer ideias ou informar o público-alvo.

A fotografia é a linguagem cultural de quem a elaborou e resultado de suas percepções. Nesta perspectiva ela se torna interessante nas ações educativas para o idoso exercitar sua sensibilidade, criatividade, cientificidade, experiências, emoções, autoconhecimento e expressar seu ponto de vista sobre as pessoas, sobre a cidade, sobre a vida.

Vale ressalta-se que as práticas sociais contemporâneas são regidas com e por registros visuais. Tudo identificado por imagens, até mesmo a linguagem entre as pessoas. Em alguns casos trocam as palavras por figuras, selfies ou fotografias de celular, smartphone ou câmeras digitais que enviam fotos por wi-fi diretamente para as redes sociais.

$\mathrm{O}$ ato de fotografar ensina ao idoso alguns princípios importantes que podem e devem ser aplicados em sua vida diária. Leva-o a refletir que uma mesma situação pode ser vista sob vários ângulos e que o sujeito fotografante pode determinar o ângulo do registro que ele quer levar consigo. Além disso, ainda agrega as seguintes dimensões ao ato educativo:

- Dimensão afetiva: habilidades para posicionar-se corajosamente diante das situações cotidianas com confiança em si mesmo, consciente de suas potencialidades como de seus limites;

- Dimensão cognitiva: capacidade para comunicar ideias, opiniões e sentimentos em distintas formas de expressão de maneira coerente e fundamentada em uma leitura de mundo equilibrada;

- Dimensão sócio-cultural: conhecer e valorizar a história social das comunidades, suas tradições, similitudes, distinções, patrimônios, valores e costumes em constante processo de construção/desconstrução/ reconstrução;

- Dimensão ética: respeitar a diferenças individuais, diversidade cultural dos espaços sociais, distintas crenças ou pensamentos divergentes, reconhecendo sempre o diálogo como fonte mediadora das diferenças;

- Dimensão profissional: valorizar a perseverança, o respeito mútuo, o esforço e o risco no cumprimento de tarefas, utilizar a flexibilidade diante dos fatos imprevistos, aceitação de conselhos e críticas nas relações interpessoais;

Lições sobre a liberdade de expressão com responsabilidade social, exercícios de construção do conhecimento transformador e a garantia de respeito mútuo são possíveis de serem consolidadas com ações pedagógicas que exploram registros fotográficos.

Somente uma educação que esteja disposta a considerar o idoso como sujeito de sua própria aprendizagem, valorize suas 
experiências de vida e sua forma de enxergar e ler o mundo, pode agregar qualidade ao envelhecimento essencialmente ativo.

\section{A fotografia como elemento didático provocativo de expressão e comunicação de conhecimentos}

O fato de a fotografia provocar lembranças e suscitar reflexões permitiu que sua exploração em ações educativas para 34 idosos matriculados na UEMA/UNABI Campus Bacabal, ampliassem seus olhares sobre o ambiente físico e social que pertencem, analisando-o com o filtro dos anos de experiências de vida e revelando-o em concepções particulares que só o click do registro fotográfico foi capaz de reproduzir. Utilizou-se parâmetros da pedagogia paulofreireana porque ela orienta ações didáticas que elegem o diálogo reflexivo e a liberdade da ação consciente como cerne do processo ensino-aprendizagem (FREIRE, 1980, 1999, 2005).

Neste propósito as tarefas educativas orientavam o idoso a aproximar-se do objeto de estudo até encontrar o melhor ângulo para enfrentá-lo, desmistificá-lo e expressá-lo, numa ação consciente de autonomia cognitiva e construção de saberes.

A exploração didática da fotografia como recurso de ensino apropriado para idosos foi metodologicamente escolhida para cumprir as exigências das diretrizes curriculares de seu projeto pedagógico próprio das quais destaca-se:

- A ação educativa é consciente e intencional.

- São condições necessárias para a construção de conhecimentos:

- - o sujeito precisa querer, sentir necessidade de apreender o objeto de estudo;
- $\quad$ - o sujeito precisa ter estrutura de assimilação para compreender o objeto de estudo;

- Para construir um conhecimento novo, o sujeito precisa de:

- $\quad$ - representações mentais prévias relativas ao objeto de estudo;

- $\quad$ - capacidade de operar com estas representações, bem como construir/ reconstruir novos conhecimentos;

- O conhecimento não se dá de uma vez (não é linear) mas por aproximações sucessivas (avanços, recuos, estagnações) visando sínteses em níveis cada vez mais amplos.

Entende-se na comunidade cientifica da Universidade Estadual do Maranhão que ensinar pessoas com longas e distintas experiências de vida não pode se limitar à transferência de informações a um ser passivo, mas considerar (e não subestimar) os saberes de sua experiência.

Partindo desses saberes e sem 'ficar nele' porque há muita vida inteligente - e conscientemente produtiva - na terceira idade, as atividades didáticas que utilizaram a fotografia como recurso de aprendizagem foram desenvolvidas com os seguintes objetivos pedagógicos:

- Analisar pessoas, lugares ou objetos a partir dos elementos da linguagem fotográfica;

- Observar o ambiente em que vive fotografando aspectos significativos da realidade;

- Fotografar uma situação social que expresse relações interpessoais afetivas e significativas para si mesmo;

- Refletir sobre mensagens transmitidas por imagens fotográficas, ressaltando seus múltiplos pontos de vista e seu valor como documento social;

Exemplificando o valor didático da fotografia na educação para idosos serão 
descritas três situações pedagógicas vivenciadas na UEMA/UNABI Campus Bacabal.

\section{a) A linguagem fotográfica}

Inicio - Aula Dialogada

- Explique que vão aprender a analisar fotografias para descobrir a mensagem que transmitem.

- Provoque os seguintes questionamentos:

- Vocês gostam de fotografias?

- Que tipo de fotografias vocês mais gostam? Por que?]

- Vocês tiram suas próprias fotografias?

Como? Celular? Câmera Digital?

- Vocês tiram selfies?

- Quem vocês gostariam de fotografar?

- Onde vocês gostariam de fotografar?

- O que você não fotografaria nunca?

\section{Desenvolvimento}

- Projete uma fotografia no Datashow e convide os idosos para mostrar distintos elementos que compõe a fotografia;

- Mostre a fotografia sem contar nada sobre a história da fotografia e fique observando suas reações. Provoque respostas pessoais com as seguintes perguntas:

- O que vocês estão olhando nesta fotografia?

- Quem é esta senhora?

- Que expressão está no rosto dela?

- O que ela está fazendo?

- Onde ela está?

- Estará feliz? Por que?

- Como será a personalidade dela?

- Quem tirou esta foto?

- O que queriam transmitir com esta foto?

- Em seguida repasse as informações que você tem sobre a fotografia tais como nome do fotógrafo, data que ela foi tirada, local, entre outras informações gerais sobre a situação ou historia do registro fotográfico.
- Explique que o registro fotográfico é apenas um recorte da realidade e que é necessário outras informações para compreender uma situação e não apenas um ângulo fotografado.

\section{Conclusão}

- Convide os idosos a expressar oralmente o conceito que ele construiu sobre 'A fotografia e sua mensagem'.

b) Elementos subjetivos da realidade social comunicadas em fotografias

Inicio - Consolidação de Aprendizagem

- Explique em sala de aula que os idosos vão tirar fotografias e depois farão uma exposição delas. Diga-lhes que vão utilizar as lições aprendidas e que as fotografias podem ser feitas por celular, smartphone, tablet ou camêra digital.

\section{Desenvolvimento}

- Peça-lhes que individualmente tirem três fotos de animais, pessoas, ou objetos no ângulo que quiserem, contando que ele goste muito e considere importante;

- Antes de descarregar as fotos dos idosos no computador para serem apresentadas no datashow diga-lhes que cada um deve escolher apenas uma fotografia para projetar;

- Solicite que o idoso relate porque escolheu aquela fotografia; Reflitam a resposta dada. Faça o mesmo com todos;

- Conversem sobre o que é importante para os homens serem felizes; sobre as similitudes e distinções das fotografias escolhidas;

- A partir do diálogo realizado escolham um titulo para o conjunto das fotografias.

- Faça-os definir que valores sociais, costumes, sentimentos ou patrimônio cultural circulam pelas fotografias. 


\section{Conclusão}

- Finalize a aula solicitando que cada um escreva uma frase sobre a mensagem social que sua fotografia comunica. E se for possível revelem as fotos e, junto às frases, exponha em local público.

\section{c) O Projeto pedagógico “Decifra-me”} aplicado.

Eis a estrutura do projeto pedagógico

NOME: PROJETO 'DECIFRA-ME'

PÚBLICO-ALVO: estudantes da UEMA/

UNABI - Campus Bacabal

UNIVERSO DA PESQUISA: a cidade de Bacabal-MA

- EIXO CONDUTOR

Quem sou eu? Onde estou?

\section{- INTENÇÕES EDUCATIVAS}

- Percepção da personalidade e temperamento pessoal com registros fotográficos; - Reflexão sobre as relações interpessoais e práticas sócio-culturais cotidianas do idoso com registros fotográficos;

\section{- D I S C I P L I N A S / C O N T E Ú D O S TRABALHADOS}

Disciplinas: Psicologia do Envelhecimento e Vida e Espiritualidade

Conteúdo: As armadilhas do eu

\section{- JUSTIFICATIVA}

Os idosos precisam saber que 'a armadilha do eu' ocorre quando ele tenta se identificar com uma autoimagem idealizada, sofrerão decepções todas as vezes que a vida o puser diante de uma situação que esse disfarce ou máscara social não possa ser mantido. Aceitar-se com virtudes e defeitos é a melhor forma de ser feliz.

\section{- ATIVIDADES}

- Diálogo informal sobre os perigos do 'eu idealizado';
- Representação do 'eu pessoal x eu social' através de um desenho em sala de aula precedido de comunicação individual que expliquem o 'eu' do desenho elaborado pelo idoso;

- Escolher imagens visuais que retratem características pessoais da identidade cultural do idoso em seu dia-a-dia, respeitando suas singularidades e tipos de comunicação;

- Diálogos sobre a história da escolha do nome do idoso, o significado etimológico e valor sentimental;

- Tirar fotografias em preto e branco ou colorida na comunidade, ressaltando os elementos fotográficos que melhor signifiquem as armadilhas do 'eu' pessoal e social na terceira idade.

- Organização de uma Exposição Fotográfica com registros fotográficos dos idosos;

- Reflexão sobre as atividades vivenciadas;

\section{- RECURSOS}

Câmera digital, smarthphone, tablet, notebook e projetor de slides.

\section{- DURAÇÃO}

Uma semana letiva.

- CULMINÂNCIA

Exposição fotográfica com o tema “As armadilhas do eu” no pátio interno da UEMA/Campus Bacabal.

\section{- PERSPECTIVAS}

Espera-se que as atividades propostas possam favorecer aos idosos a consciência de que possuem em si virtudes e defeitos, mas estes não impedem que vivam felizes.

\section{- REFERENCIAS}

BOUDIER, P. A ilusão biográfica. In: Razões práticas: sobre a teoria da ação. São Paulo: Papirus, 1997. 
BOSI, E. Memória e sociedade: lembranças de velhos. São Paulo: Companhia das Letras, 1994

Lembranças de velhos. São Paulo: T.A. Queiroz; EDUSP, 1987.

\section{As aprendizagens construídas}

Uma vez assumido que os seres humanos são seres em processo constante de humanização, mas que, ao mesmo tempo, devido às situações históricas específicas encontram-se desumanizados, os idosos descobriram que a liberdade implica necessariamente em denuncia $\mathrm{x}$ anúncio, comunicação e expressão de si, do outro, da vida. E a reconheceram que, mesmo na velhice, podem fazer diariamente este exercício e registro civil pela fotografia, legitimados pelo valor de documento social que ela confere a todos, sem distinção.

Neste processo educativo os idosos desnudam as desigualdades e opressões sociais na mesma medida em que vão comprometendo-se, na práxis, com as mudanças sociais e pessoais subjetivas, mas passíveis de serem comunicadas e/ou fotografadas.

\section{Considerações finais}

Ações educativas que usam a fotografia como recurso didático podem alcançar aprendizagens sociais significativas tais como crescimento pessoal do idoso com a ampliação do conhecimento de si mesmo assim como a identificação de suas reais potencialidades e limitações nas situações cotidianas. Além disso a exposição didática com o auxilio de registros fotográficos ampliam sua competência comunicativa pela otimização das habilidades de avaliar, selecionar ângulos, ideias, opiniões, sentimentos, fazendo uso de diversas e variadas formas de expressão.
Cognitivamente as habilidades de interpretação, analise e síntese de informações dos idosos foram aperfeiçoadas e com isso melhoraram suas condições de avaliar e estabelecer relações entre parte $\mathrm{x}$ todo, essência x aparência, distinguindo similitudes e distinções, comunicando informações com responsabilidade social.

Em relação à formação ética do idoso brasileiro a exploração da fotografia como recurso didático auxilia em situações de aprendizagem que valorizem o respeito mútuo, a diversidade cultural e seus distintos espaços sociais reconhecendo o diálogo como instrumento social permanente de humanização e superação das diferenças individuais.

A educação para idosos deve respeitá-lo como ser social que ele é. Sua história de vida é patrimônio cultural da sociedade brasileira. Fotografe-o.

\section{Referencias}

ALVES, R. As cores do crepúsculo: a estratégia do envelhecer. Campinas: Papirus, 2001.

BOSI, E. Memória e sociedade: lembranças de velhos. São Paulo: Companhia das Letras, 1994.

. Lembranças de velhos. São Paulo:

T.A. Queiroz; EDUSP, 1987.

BOTH, A. Identidade existencial na velhice: mediações do Estado e da Universidade. Passo Fundo: UPF, 2000.

BOUDIER, P. A ilusão biográfica. In: - Razões práticas: sobre a teoria da ação. São Paulo: Papirus, 1997.

BRASIL. SECRETARIA DE DIREITOS HUMANOS. SECRETARIA NACIONAL DE PROMOÇÃO DEFESA DOS DIREITOS HUMANOS. Dados sobre o 
envelhecimento no Brasil. Disponível em: < http://www.civico.com.br/ idoso/05seminarioIdosoApresenta.asp> Acesso em 20 abr. 2016.

DUBOIS, P. O ato fotográfico e outros ensaios. Campinas, Papirus, 1994.

FREIRE, P. A educação como prática da liberdade. 23 ed. Rio de Janeiro: Paz e Terra, 1999.

- Conscientização: teoria e prática da libertação. São Paulo: Moraes, 1980.

Pedagogia do oprimido. Rio de Janeiro: Paz e Terra, 2005.

KOSSOY, B. Fotografia e história. São Paulo: Ateliê Editorial, 2003.

LIMA, M. P. Gerontologia educacional: uma pedagogia específica para o idoso uma nova concepção de velhice. São Paulo: LTR, 2000.

MONTEIRO, P. P. Envelhecer: histórias, encontros, transformações. Belo Horizonte: Autentica, 2001.

NERI, A. L. (Org.). Psicologia do envelhecimento. Campinas SP: Papirus, 1995.

SOARES, M. Letramento: um tema em três gêneros. Belo Horizonte: Autentica, 1999.

STAMATTO, M. I. S. A fotografia em pesquisas históricas. In: ANDRADE, J. M. V.; STAMATTO, M. I. S. (Orgs.) História ensinada e a escrita da história. Natal-RN: EDUFRN, 2009.

VERAS, R. (Org.). Terceira idade: desafios para o terceiro milênio. Rio de Janeiro: Relume Dumará: UnATI/UERJ, 1997 